\title{
Comparison of Neonatal Apgar Score \& Umbilical Artery Blood Gas Parameters Among parturients Undergoing Elective Caesarean Section Under Spinal, Epidural \& General Anaesthesia: A Prospective Randomized Observational Study
}

\author{
Pratibha Jain Shah, Deepak Singh and Sonali Sahu* \\ Department of anaesthesiology and critical care, Pt. Jawahar Lal Nehru Medical College, India
}

Submission: February 27, 2017; Published: April 06, 2017

*Corresponding author: Sonali Sahu, Department of anaesthesiology and critical care, Pt. Jawahar Lal Nehru Medical College, Raipur, Chhattisgarh, India, Tel: 8827098171; Email: dr.sonalisahu89@gmail.com

\section{Abstract}

Introduction: Frequency of lower segment caesarean section (LSCS) is increasing today. All anaesthetic techniques used for LSCS may have certain advantages \& disadvantages that affect short and long term neonatal outcome. This study aimed to compare effect of spinal, epidural and general anaesthesia on neonatal outcome in terms of Apgar score and umbilical arterial (UA) blood gas parameters.

Method: Total 90 parturients belonging to age group of 20-30 yrs of ASA grade I and II who were scheduled to undergo elective LSCS were randomly allocated by chit method into three groups $(\mathrm{n}=30)$. Group SA received spinal anaesthesia, Group EA received epidural anaesthesia and Group GA received general anaesthesia. Duration between induction to skin incision (I-SI), skin incision to delivery (SI-D) and uterine incision to delivery (UI-D) were noted. Intraoperative vitals like HR, SBP, DBP, RR, SPO2 and ETCO2 at various time intervals were recorded. Neonatal UA blood gas parameters (pH, PO2, PCO2, $\mathrm{HCO}, \mathrm{BE}$ ) and Apgar score (at 1 and 5 minutes) were assessed after delivery of baby.

Result: Demographic profiles of parturients were comparable. Intraoperative episode of hypotension found more in group SA than group EA and GA. Mean Apgar score at 1 min, mean UA blood pH and PO2 were significantly low and mean UA blood PCO2 was significantly high in group SA and GA as compared to group EA ( $p<0.05)$ but difference in Apgar score at $1 \mathrm{~min}$, mean UA blood pH, PO2 and PCO2 were statistically insignificant between Group SA and GA. (p>0.05) Mean Apgar score at 5 min, mean UA HCO3 and BE values were statistically insignificant and comparable among groups. ( $\mathrm{p}>0.05)$.

Conclusion: All three anaesthetic techniques were safe for neonates in elective LSCS, but epidural anaesthesia was associated with better short term neonatal outcome as compared to spinal and general anaesthesia for elective LSCS.

Keywords: Spinal; Epidural; General anaesthesia; Apgar score; UA blood gas analysis

Abbreviations: LSCS: Lower Segment Caesarean Section; UA: Umbilical Arterial; I-SI: Induction to Skin Incision; SI-D: Skin Incision to Delivery; UI-D: Uterine Incision to Delivery

\section{Introduction}

Lower segment caesarean section (LSCS) is a life-saving procedure for the parturient and her baby. The frequency of caesarean section continues to rise steadily worldwide [1]. Today, caesarean delivery accounts for more than $30 \%$ of all births [2]. In India the incidence of LSCS is increased from 3\% to $10 \%$ between 1992-93 and 2005-06 [3]. Anaesthesia to a parturient affects both mother and fetus, so anaesthesiologist has to look over both individuals. The type of anaesthesia administered for LSCS is an important determinant of the short term and long term maternal and neonatal outcome. Each anaesthesia method for elective LSCS has their own advantages and disadvantages to both mother and neonate. Anaesthesiologist must choose the type of anaesthesia that is safe for mother, have least depressant effect on neonate and provides optimal working conditions 
for the obstetricians [4]. The spinal anaesthesia is commonly used method for LSCS, because of simple and quick technique, requires low volume of drugs for induction, less or no systemic effects to the baby, low risk of maternal pulmonary aspiration and an awake mother at the time of delivery but associated with high risks of an extensive block, fixed duration of anaesthesia, post-dural puncture headache and high incidence of maternal hypotension followed by decrease uterine blood flow in placenta, thus impair fetal acid base status even in an existence of a normal placental store [5-8].

Epidural block for LSCS has increased in popularity due to its benefits like low incidence of maternal hypotension and neonatal respiratory depression, less or no postoperative pain and discomfort to mother. Though general anaesthesia is associated with good control of airway and ventilation, better maintenance of cardiovascular stability, but the drugs required for general anaesthesia are multiple and may produce systemic effects in the baby like low Apgar score and sedation, directly by placental transfer and indirectly by maternal physiological and biochemical changes. General anaesthesia is also associated with maternal risks of difficult intubation, pulmonary aspiration, delayed recovery, nausea and vomiting [9]. The incidence of maternal mortality may reach up to $10 \%$ under general anaesthesia [10]. Apgar score and umbilical artery $\mathrm{pH}$ known to provide best measures of neonatal outcome after LSCS under all three types of anaesthesia and both can be affected by alterations in the cord blood flow with the delivery process and different anaesthesia techniques [11]. Due to benefits and risks of the different anaesthetic techniques, it is important to choose safest anaesthesia for good maternal and neonatal outcomes irrespective of indications of caesarean section.

No ideal anaesthetic method for minimizing adverse neonatal outcome has yet been described in literatures. Uniform data available regarding comparative effects of types of anaesthesia on cord blood gases of neonates in healthy maternal population are limited. So the aim of present study was to determine the effect of spinal, epidural and general anaesthesia on neonatal outcome in terms of Apgar score and umbilical cord blood gas values in elective LSCS. So that we can standardize the anaesthesia technique for elective caesarean section that have least effect on neonatal outcome.

\section{Method}

This study was conducted in the Department of Anaesthesiology and Critical care, Pt. J.N.M. Medical College \& Dr. B.R.A.M. Hospital Raipur, C.G, after approval from the institutional ethics committee. This prospective, randomized, open label observational study was done in total 90 parturient belonging to the age group of 20-30 yrs, ASA grade I \& II, who were scheduled to undergo LSCS under spinal, epidural and general anaesthesia. The Parturients were randomly divided by chit method into three groups of 30 parturients in each group $(n=30)$, Group SA received spinal anaesthesia; Group EA received epidural anaesthesia and Group GA received general anaesthesia. Before the study, a power of study was calculated by using software $G$ Power 3.0.10, taking mean values from the study of Petropoulos $\mathrm{G}$ et al [12] and considering a probability level of 0.05 ( $\alpha$-error) and power of 0.80 (1- $\beta$ ) yielded a sample size of 30 parturients for each group. Parturients complicated with following conditions were excluded from the study: Anaemia $(<10 \mathrm{gm} / \mathrm{dl})$, severe PIH, placenta previa, abruptio placenta, oligohydramnios, gestational diabetes mellitus, morbidly obese (BMI > $40 \mathrm{~kg} /$ $\mathrm{m}^{2}$ ), major cardiac abnormalities, congenital malformations, intrauterine growth retardation and fetal distress. Induction to delivery time $>10$ minutes, skin incision to delivery time $>8$ minutes and uterine incision to delivery time $>3$ minute were also excluded from the study.

Pre-anaesthetic evaluation was carried out and written informed consent was obtained either from the parturient or from her relatives to carry out the procedure and enrolled her in this study after explanation. In operation theatre multipara monitor (Philips MP 30) was applied to monitor non-invasive blood pressure, $\mathrm{ECG}, \mathrm{SPO}_{2}$ and $\mathrm{ETCO}_{2}$. Intravenous line was maintained by inserting $18 \mathrm{G}$ i.v. cannula in vein of dorsum of hand. Premedication was given with inj. Ranitidine $50 \mathrm{mg}$ i.v. and inj. metoclopramide $10 \mathrm{mg}$ i.v. $30 \mathrm{~min}$ before induction to all the parturient. Parturients were induced with particular anaesthesia according to groups assigned. In group SA, with all aseptic precautions subarachnoid space was approached at $\mathrm{L}_{3}$ $\mathrm{L}_{4}$ or $\mathrm{L}_{4}-\mathrm{L}_{5}$ interspace with $26 \mathrm{G}$ Quincke spinal needle in sitting position. Inj. Bupivacaine 0.5\% (heavy) $2 \mathrm{ml}$ was injected and parturient was placed in supine position immediately. A tilt of 10-15 degree was given to achieve appropriate block height. Block height was checked by spirit swab for temperature sensation. Parturients in group EA were placed in sitting position and with all aseptic precautions epidural space was approached and identified by loss of resistance method at L3-L4 or L4-L5 interspace, epidural catheter was inserted, left in situ and fixed. Inj. After injection of test dose of Lignocaine with adrenaline $2 \%$, $3 \mathrm{ml}$, Inj. Bupivacaine 0.5\%, $12 \mathrm{ml}$ were given. Block height was checked by spirit swab for temperature sensation. In group GA, parturients were induced with i.v. Thiopentone sodium 5-7 mg/ $\mathrm{kg}$ after 3 min preoxygenation with $100 \% \mathrm{O}_{2}$. Inj. Succinylcholine $1.5 \mathrm{mg} / \mathrm{kg}$ i.v. was given to facilitate tracheal intubation. Trachea was intubated with 7-7.5 mm cuffed endotracheal tube. After checking bilateral air entry, tube was fixed.

Depth of anaesthesia was maintained with $\mathrm{O}_{2}: \mathrm{N}_{2} \mathrm{O} 50 \%: 50 \%$, isoflurane and muscle relaxant i.v. Atracurium $0.5 \mathrm{mg} / \mathrm{kg}$ bolus followed by maintenance dose $0.1 \mathrm{mg} / \mathrm{kg}$. At the end of surgery, when parturient resumed some breathing effort, residual effects was reversed with i.v. Neostigmine $0.05 \mathrm{mg} /$ $\mathrm{kg}$ and i.v. Glycopyrrolate $0.01 \mathrm{mg} / \mathrm{kg}$. When the patients were fully awake then the endotracheal tube was removed with oral suction. Hypotension defined as fall in baseline SBP $>20 \%$ was corrected with intravenous crystalloid fluid, if persist then i.v. Mephentermine 6 mg incremental dose was given. Bradycardia 
$(\mathrm{HR}<60)$ was corrected with i.v. Atropine 0.6 mg. ECG, Heart rate, Systolic blood pressure, Diastolic blood pressure, Respiratory rate, Oxygen saturation and End tidal $\mathrm{CO}_{2}$ were recorded throughout the procedure and note at the time of induction and at every 2 minute after induction till delivery of baby. Induction to skin incision, skin incision to delivery and uterine incision to delivery time were also noted. Umbilical artery blood sample was taken from a double clamped segment of umbilical cord and umblical arterial blood gas analysis was immediately done using COBAS 121 ABG machine. Apgar score of neonate at 01 and 05 minutes after delivery of the neonate were assessed. Statistical analysis was done using Graph pad prism 7 software. Data were analyzed by One way ANOVA test and Tukey's multiple comparison test. Tukey's multiple comparison tests was used for multiple pair wise group comparison. The results were analyzed by various statistical techniques like percentage, mean and standard deviation. p- Value $<0.05$ considered significant finding.

\section{Results}

Table 1: Demographic profile and time intervals (Mean $\pm S D$ ).

\begin{tabular}{|c|c|c|c|c|}
\hline & Group SA & Group EA & Group GA & P-value \\
\hline $\begin{array}{c}\text { Maternal } \\
\text { age (yrs) }\end{array}$ & $24.47 \pm 2.60$ & $24.80 \pm 1.86$ & $25.03 \pm 2.47$ & $>0.05$ \\
\hline $\begin{array}{c}\text { Maternal } \\
\text { wt (kg) }\end{array}$ & $54.77 \pm 5.04$ & $55.57 \pm 4.79$ & $53.33 \pm 4.85$ & $>0.05$ \\
\hline $\begin{array}{c}\text { Maternal ht } \\
\text { (cms) }\end{array}$ & $152.2 \pm 3.02$ & $153.3 \pm 3.56$ & $151.3 \pm 4.84$ & $>0.05$ \\
\hline $\begin{array}{c}\text { Baby wt } \\
\text { (kg) }\end{array}$ & $3.007 \pm 0.21$ & $3.012 \pm 0.17$ & $3.027 \pm 0.18$ & $>0.05$ \\
\hline $\begin{array}{c}\text { Induction } \\
\text { - skin } \\
\text { incision } \\
\text { time (min) }\end{array}$ & $1.403 \pm 0.07$ & $1.424 \pm 0.10$ & $1.410 \pm 0.07$ & $>0.05$ \\
\hline $\begin{array}{c}\text { Skin } \\
\text { incision - } \\
\text { delivery } \\
\text { time (min) }\end{array}$ & $5.423 \pm 0.22$ & $5.417 \pm 0.28$ & $5.427 \pm 0.25$ & $>0.05$ \\
\hline $\begin{array}{c}\text { Uterine } \\
\text { incision - } \\
\text { delivery } \\
\text { time(min) }\end{array}$ & $1.5 \pm 0.12$ & $1.5 \pm 0.13$ & $1.5 \pm 0.14$ & $>0.05$ \\
\hline
\end{tabular}

The maternal and neonatal demographic profiles, induction to skin incision time, skin incision to delivery time and uterine incision to delivery time were statistically comparable among three groups ( $p>0.05$ ) (Table 1 ). Highly significant fall in maternal HR from baseline was seen just after induction, at $2 \mathrm{~min}, 4 \mathrm{~min}$ and 6 min in group SA and group EA than group GA $(\mathrm{p}<0.001)$ but bradycardia was not seen in any parturients and none of the parturient required atropine (Figure 1). Highly significant fall in SBP and DBP from baseline was seen at $4 \mathrm{~min}$ and 6 min in group SA than group EA and group GA. $(\mathrm{p}<0.0001)$ The difference in mean SBP and DBP was statistically insignificant between group EA and group GA. ( $>>0.05)$ (Figures 2\&3) 3 patients in group SA had episode of hypotension that was not severe and did not require vasopressure. None of the patient in group EA and group GA had experienced episode of hypotension. Respiratory parameters $\mathrm{RR}, \mathrm{SPO}_{2}$ and $\mathrm{ETCO}_{2}$ were comparable in all three groups. Mean Apgar score of neonates at 1 minute was significantly low in both group SA and group GA as compared to group EA. This difference was statistically highly significant between group GA and EA but only significant between group SA and EA. Difference in mean Apgar score at 1 min between groups SA \& GA was insignificant. ( $>0.05)$ Mean Apgar score at 5 minute was statistically insignificant among groups. ( $p>0.05)$ Mean UA pH and $\mathrm{pO}_{2}$ were significantly low while mean UA pCO2 was significantly high in group SA and GA as compared to group EA. $(\mathrm{p}<0.05)$ Difference in $\mathrm{UA} \mathrm{pH}, \mathrm{pO}_{2}$ and $\mathrm{pCO}_{2}$ values were statistically insignificant between SA \& GA groups. ( $p>0.05)$ The difference in mean $\mathrm{UA} \mathrm{HCO}_{3}$ and $\mathrm{BE}$ was statistically insignificant among groups ( $\mathrm{p}>0.05)$ (Table 2$)$.

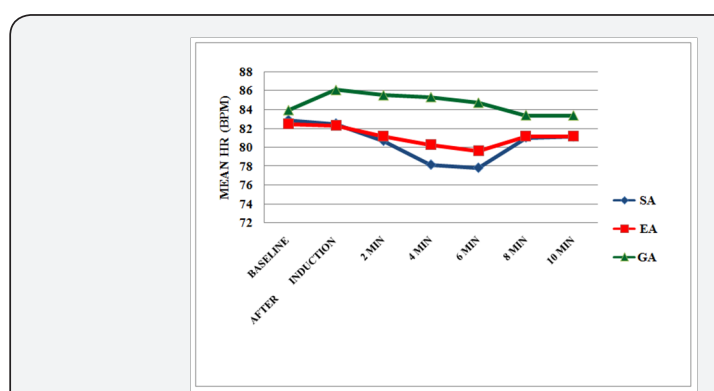

Figure 1: Mean Heart Rate (in BPM) at various time intervals.

Table 2: Apgar score at $1 \& 5$ min \& Umblical arterial blood gas parameters (Mean \pm SD).

\begin{tabular}{|c|c|c|c|c|c|c|}
\hline & Group SA & Group EA & Group GA & SA VS. EA & SA VS. GA & EAVS. GA \\
\hline Apgar $1 \mathrm{~min}$ & $7.967 \pm 0.55$ & $8.467 \pm 0.62$ & $7.848 \pm 0.71$ & 0.0084 & 0.6778 & 0.0006 \\
\hline Apgar 5 min & $9.867 \pm 0.34$ & $9.90 \pm 0.30$ & $9.767 \pm 0.43$ & 0.9331 & 0.5396 & 0.3365 \\
\hline $\mathrm{UA} \mathrm{pH}$ & $7.252 \pm 0.03$ & $7.294 \pm 0.04$ & $7.238 \pm 0.03$ & $<0.0001$ & 0.3263 & $<0.0001$ \\
\hline $\mathrm{UA} \mathrm{pO}(\mathrm{mmHg})$ & $24.42 \pm 1.81$ & $26.06 \pm 1.78$ & $24.24 \pm 2.2$ & 0.0036 & 0.9287 & 0.0011 \\
\hline $\mathrm{UA} \mathrm{pCO}(\mathrm{mmHg})$ & $50.48 \pm 1.67$ & $45.1 \pm 1.83$ & $52.71 \pm 1.22$ & 0.0174 & 0.4788 & 0.0005 \\
\hline $\begin{array}{c}\mathrm{UA} \mathrm{HCO} \\
(\mathrm{mmol} / \mathrm{L})\end{array}$ & $22.79 \pm 1.6$ & $22.07 \pm 1.3$ & $22.91 \pm 1.1$ & 0.5308 & 0.9843 & 0.4295 \\
\hline $\mathrm{UA} \mathrm{BE}(\mathrm{mmol} / \mathrm{L})$ & $-4.97 \pm 2.4$ & $-4.22 \pm 2.4$ & $-4.98 \pm 1.6$ & 0.3926 & 0.9997 & 0.3797 \\
\hline
\end{tabular}




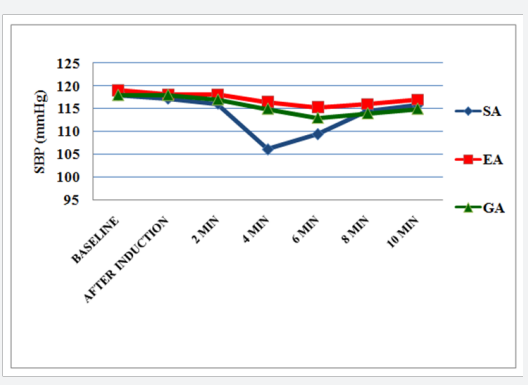

Figure 2: Mean Systolic Blood Pressure (in $\mathrm{mmHg}$ ) at various time intervals.

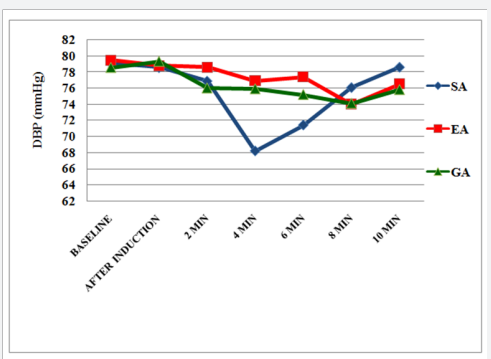

Figure 3: Mean Diastolic Blood Pressure (in $\mathrm{mmHg}$ ) at various time intervals

\section{Discussion}

As with increasing incidence of LSCS in India, the role of anaesthesiologist is also increased. Since beginning spinal anaesthesia has been used for LSCS but it is associated with maternal hypotension which impairs uteroplacental flow. In our study heart rate was decreased from baseline in both spinal and epidural anaesthesia group but bradycardia (HR <60 per min) was not seen in any parturients. Heart rate was significantly raising in general anaesthesia group after induction which was due to sympathetic stimulation during laryngoscopy. Abdallah MW et al [13] also observed tachycardia after induction in general anaesthesia group. Incidence of hypotension was 10\% (3 of 30 parturients) in spinal anaesthesia group in our study, but none of them required vasopressure. We observed no episode of hypotension in epidural and general anaesthesia groups. Similar result was observed by Tonni $\mathrm{G}$ et al, Mekonnen S et al and Saygi A et al [14-16]. Frequency of hypotension observed in studies of Kolatat $\mathrm{T}$ et al [17] (56.8\% in spinal anaesthesia \& $51.3 \%$ in epidural anaesthesia) and Sener EB et al [18] (51\% in epidural anaesthesia) were more as compared to our study.

This could be due to drugs used by them i.e. Kolatat $\mathrm{T}$ et al [17] used $1.2 \mathrm{ml}$ 5\% Lignocaine for spinal block and $20 \mathrm{ml}$ of $2 \%$ Lignocaine with Adrenaline for epidural block and Sener E B et al [18] used $20 \mathrm{ml}$ of $0.325 \%$ Bupivacaine, were different from our study. In our study 1 min Apgar scores were low in spinal and general anaesthesia as compared to epidural anaesthesia, but 5 min Apgar scores were statistically comparable among groups. Gori F et al, Rasooli S et al and Saygi A et al $[1,19,16]$ also found similar results in their studies. Hypotension in spinal anaesthesia and depressant effect of drugs used for induction of general anaesthesia might be responsible for low 1 min Apgar score. But these effects are short term and do not affect $5 \mathrm{~min}$ Apgar score. Mean UA pH was significantly low in spinal and general anaesthesia as compared to epidural anaesthesia but UA $\mathrm{pH}<7.15$ (acidemia) was not observed in our study. We also found no significant difference in mean UA pH between spinal and general anaesthesia. Similar findings were observed by Kolatat T et al, Sener EB et al, Tonni G et al, Strouch ZY et al and Rasooli $\mathrm{S}$ et al $[14,17-20]$. In our study $\mathrm{UA} \mathrm{PO}_{2}$ was significantly low and $\mathrm{PCO}_{2}$ was significantly high in spinal and general anaesthesia as compared to epidural anaesthesia, while no significant difference was found in $\mathrm{UA}_{\mathrm{HCO}}$ and $\mathrm{BE}$ values among groups and all these parameters were within normal limits.

Kolatat T et al, Petropoulos G et al, Tonni G et al, Abdallah MW et al and Rasooli S et al $[17,12,13,14,19]$ observed similar findings regarding $\mathrm{UA} \mathrm{PCO}_{2}, \mathrm{HCO}_{3}$ and BE. Kolatat T et al [17], Petropoulos G et al [12] and Tonni G et al [14] found high UA $\mathrm{PO}_{2}$ in general anaesthesia group and their results were different from our study. They explained it, that high maternal inspired $\mathrm{O}_{2}$ concentration in general anaesthesia result to high $\mathrm{UA} \mathrm{PO}_{2}$ in neonates. Long intervals including induction to delivery time $>10$ minutes, skin incision to delivery time $>8$ minutes and uterine incision to delivery time $>3$ minutes adversely affects neonatal outcome by decreasing uteroplacental blood flow, but these intervals are within normal limits in our study. Limitation of our study was small sample size and also we have not done maternal arterial blood gas analysis which might be the reason for the neonatal acid base imbalance. Further study with large sample size including both maternal and neonatal arterial blood gas analysis should be done to evaluate the effects of anaesthesia techniques on neonatal outcome.

\section{Conclusion}

We concluded that spinal anaesthesia, epidural anaesthesia and general anaesthesia are safe for both mother and neonates as maternal blood pressure, Apgar score and umbilical arterial blood gas values are not significantly affected. However among three anaesthetic techniques, epidural anaesthesia was associated with better short term neonatal outcome and could be a preferred anaesthetic choice for elective lower segment caesarean section.

\section{References}

1. Gori F, Pasqualucci A, Corradetti F, Milli M, Peduto VA (2007) Maternal and neonatal outcome after caesarean section: The impact of anaesthesia. J Matern Fetal Neonatal Med 20(1): 53-57.

2. Betran AP, Merialdi M, Lauer JA, Bing-shun W, Thomas J, et al. (2007) Rates of caesarean section: analysis of global, regional and national estimates. Paediatr Perinat Epidemiol 21(2): 98-113.

3. IIPS and Macro international (2007) National Family Health Survey (NFHS-3), 2005-06, Volume I \& II, India.

4. Nafie HM, Ismael SA (2015) Comparing Effects of Caesarean Section using Spinal and General Anaesthesia on Neonatal Short-Term 
Outcome. International Journal of Gynaecological and Obstetrical Research 3: 60-64.

5. Kamran S, Akercan F, Akarsu T, Firat V, Ozcan O, et al. (2005) Comparison of the maternal and neonatal effects of epidural block and of combined spinal-epidural block for Caesarean section. Eur J Obstet Gynecol Rep Biol 121(1): 18-23.

6. Sukhera SA, Ahmed S (2006) Neonatal outcome: a comparison between epidural and general anaesthesia for caesarean sections. Professional Med J 13: 72-78.

7. Mueller MD, Bruhwiler H, Schupfer GK, Luscher KP (1997) Higher rate of fetal acidemia after regional anaesthesia for elective caesarean delivery. Obstet Gynecol 90(1): 131-134.

8. Roberts SW, Leveno KJ, Sidawi JE, Lucas MJ, Kelly MA (1995) Fetal acidemia associated with regional anaesthesia for elective caesarean delivery. Obstet Gynecol 85(1): 79-83.

9. Algert CS, Bowen JR, Glies WB, Knoblanche GE, Lain SJ, et al. (2009) Regional block versus general anaesthesia for caesarean section and neonatal outcomes: a population - based study. BMC Med 7: 20.

10. Reynolds F, Seed PT (2005) Anaesthesia for caesarean section and neonatal acid-base status a meta analysis. Anaesthesia 60: 636-653.

11. Sultana A. Masood Z, Hasan S (2004) Effect of type of anesthesia on neonatal outcome. Anl Abbasi Shaheed Hospital Karachi Med Dent Coll 9: 552-557.

12. Petropoulos G, Siristatidis C, Salamalekis E and Creatsas G (2003) Spinal and epidural versus general anaesthesia for elective caesarean Section at term; effect on the acid-base status of the mother and newborn. Journal of Maternal-Fetal and Neonatal Medicine 13(4): 260-266.

13. Mai Wedad Abdallah, Nashwa Sami Elzayyat, Mohamed Mohamed Abdelhaq, Ahmed Ali Mohamed Gado (2014) A comparative study of general anaesthesia versus combined spinal-epidural anaesthesia on the fetus in caesarean section. Egyptian Journal of Anaesthesia 30(2): 155-160.

14. G Tonnia, B Ferrarib, C De Felicec, A Ventura (2007) Fetal acid-base and neonatal status after general and neuraxial anaesthesia for elective Caesarean section. International Journal of Gynecology \& Obstetrics 97(2): 143-146.

15. Semagn Mekonnen, Kokeb Desta (2016) Effects of Types of Anaesthesia on Neurobehavioral Response and Apgar score in Neonates Delivered with Caesarean Section in Dilla University Referral Hospital. Journal of Anesthesia \& Clinical Research 7(7): 642.

16. Saygı AI, Ozdamar O, Gun I, Emirkadı H, Mungen E, et al. (2015) Comparison of maternal and fetal outcomes among patients undergoing caesarean section under general and spinal anaesthesia : a randomized clinical trial. sao paulo med J 133(3): 227-234.

17. Kolatat T, Somboonnanonda A, Lertakyamanee J, Chinachot T, Tritrakaran T, et al. (1999) Effect of general and regional anaesthesia on the neonate: a prospective randomized trial. J Med Assoc Thai 82(1): 40-45.

18. Sener EB, Guldogus F, Karakaya D, Baris S, Kocamanoglu S, et al. (2003) Comparison of neonatal effects of epidural and general anaesthesia for caesarean section. Gynecol Obstet Invest 55(1): 41-45.

19. Sousan Rasooli, Farnaz Moslemi (2014) Apgar scores and cord blood gas values on neonates from cesarean with general anesthesia and spinal anesthesia. J Anal Res Clin Med 2(1): 11-6.

20. Strouch ZY, Dakik CG, White WD, Habib AS (2015) Anaesthetic technique for caesarean delivery and neonatal acid-base status: a retrospective database analysis. Int J Obstet Anesth 24(1): 22-29.

\section{Your next submission with Juniper Publishers will reach you the below assets}

- Quality Editorial service

- Swift Peer Review

- Reprints availability

- E-prints Service

- Manuscript Podcast for convenient understanding

- Global attainment for your research

- Manuscript accessibility in different formats

( Pdf, E-pub, Full Text, Audio)

- Unceasing customer service

Track the below URL for one-step submission https://juniperpublishers.com/online-submission.php 